\title{
The Fixation of Tetanus Toxin by Ganglioside
}

\author{
By W. E. VAN HEYNINGEN aNd PAULINE ALLAN MILLER* \\ Sir William Dunn School of Pathology, University of Oxford
}

\author{
(Received 25 July 1960)
}

\begin{abstract}
SUMMARY
The fixation of tetanus toxin by brain ganglioside has been confirmed. A method has been developed for assaying the toxin-fixing capacity of ganglioside in the analytical ultracentrifuge. Under appropriate conditions ganglioside will fix many times its own weight of toxin. Ganglioside preparations from brain contain at least three gangliosides; at least two of these differ in their sialic acid contents and toxinfixing capacities. The sialic acid residues (and their free carboxyl groups) are essential for toxin-fixation. Tetanus toxin does not appear (so far) to bring about any change in the ganglioside molecule.
\end{abstract}

\section{INTRODUCTION}

In a previous paper (Van Heyningen, $1959 b$ ) the tetanus toxin receptor in nervous tissue was tentatively identified as ganglioside. Brain ganglioside contains fatty acid (stearic acid), sphingosine, hexose (glucose and galactose), hexosamine ( $N$ acetylgalactosamine) and sialic acid ( $N$-acetylneuraminic acid) residues. The fatty acid, sphingosine and one of the hexose residues comprise a cerebroside moiety (Klenk \& Lauenstein, 1953; Bogoch, 1958; Rosenberg \& Chargaff, 1958). The presence of hydrophobic and hydrophilic groups can lead to micelle formation in aqueous solution, and the values for a molecular weight of about 250,000 reported by Folch, Arsove \& Meath (1951), Bogoch (1958) and Rosenberg \& Chargaff (1958) may be a reflexion of such micelle formation. Klenk \& Gielen (1960) have recently reported that the ultracentrifugal behaviour of ganglioside in solution in dimethylformamide is consistent with a molecular weight of $c$. 1500. Their preparation of ganglioside appears to be a mixture of two gangliosides, for which they have suggested detailed structures. Each contains one moiety of cerebroside, one hexose residue and one sialic acid residue, and while one contains a hexosamine residue the other has an additional hexose residue instead. There is some uncertainty, however, about the sialic acid and hexosamine contents of brain ganglioside, and the reported values vary (Table 1 ).

Because of the formation of micelles in aqueous solution, conclusions about the homogeneity of preparations subjected to ultracentrifugation and electrophoresis are of questionable value. In the present work a ganglioside preparation, although electrophoretically and ultracentrifugally homogeneous, was found on investigation by chromatographic methods to contain a number of constituents. Some of these were eliminated, to leave a mixture of at least three gangliosides which were partially separated. In addition, a more refined method of assay of toxin-fixing 
capacity has been evolved. A study has been made of the effect of modifications in ganglioside on its capacity to fix toxin, and the important question of whether ganglioside is changed as a result of its interaction with toxin has been investigated.

Table 1. Sialic acid and hexosamine contents of ganglioside preparations as variously reported

Reference
Svennerholm (1956 $a, 1957 a)$
Klenk \& Gielen (1960)
Folch, Meath \& Bogoch (1956);
see also Meltzer (1958)
Bogoch (1958)
Rosenberg \& Chargaff (1958)

$\begin{array}{cc}\text { Sialic acid } & \text { Hexosamine } \\ 1.0 & 1.0 \\ \left\{\begin{array}{c}1.0 \\ 1.0\end{array}\right. & 1.0 \\ 1.5 & 0 \\ 1.5 & 0.67 \\ 1.5 & 1 \\ & 0.36\end{array}$

\section{METHODS}

Toxin. The tetanus toxin preparation, TD464D (Van Heyningen, 1959a), was kindly supplied by Dr C. G. Pope and Dr R. O. Thompson of the Wellcome Research Laboratories. It contains $40 \%$ (w/w) protein (the rest is salt); $75 \%$ of this protein is toxin.

Ganglioside. Fresh beef brain ( $8 \mathrm{~kg}$.) was freed from blood and meninges under running tap water, minced in a Waring blendor with an equal volume of acetone, centrifuged, and the acetone extract discarded. The extraction was repeated twice to yield $1.3 \mathrm{~kg}$. acetone-dried powder. This material was extracted for $5 \mathrm{hr}$. in a Soxhlet extractor with chloroform + methanol $(1+2$ vol. $)$, to yield 380 g. extract (see Svennerholm, 1956a). Four $90 \mathrm{~g}$. batches of extract were each dissolved in 3.5 l. chloroform + methanol $(2+1$ vol.) and the solutions dialysed for two days against running tapwater. During this time two phases formed within the dialysis tubes. The material in the upper aqueous phases from the four batches was concentrated in a rotating evaporator and freeze-dried to yield $14 \mathrm{~g}$. crude ganglioside containing $0.3 \mu$ mole sialic acid $/ \mathrm{mg}$. (see Folch et al. 1951). Of this crude ganglioside $10 \mathrm{~g}$. were dissolved in $400 \mathrm{ml}$. chloroform + methanol (2+1 vol.) containing $10 \%$ $(\mathrm{w} / \mathrm{v}) \mathrm{CaCl}_{2} \cdot \mathrm{H}_{2} \mathrm{O}$. After standing for some hours at room temperature the deposit was filtered off (see Rosenberg \& Chargaff, 1958), the filtrate dialysed against running tap water for two days, and the ganglioside recovered from the upper phase as before; the yield was $4 \cdot 1 \mathrm{~g}$. crude ganglioside containing $0 \cdot 6 \mu$ mole sialic acid $/ \mathrm{mg}$. This material was again dissolved in chloroform + methanol, treated with calcium chloride, and recovered by partition-dialysis to yield $3 \cdot 0 \mathrm{~g}$. ganglioside containing $0.82 \mu$ mole sialic acid $/ \mathrm{mg}$. This was the calcium salt of ganglioside. To convert it to the free acid $3 \mathrm{~g}$. were dissolved in $80 \mathrm{ml}$. water and the solution brought to $\mathrm{pH} 1.4$ with $12 \mathrm{~N}-\mathrm{HCl}$. The acidic solution was dialysed in the cold with agitation against several changes of 1 l. of distilled water until the $\mathrm{pH}$ value was constant at 8.0 (Folch et al. 1951). The final yield was $2.7 \mathrm{~g}$. of partially purified ganglioside containing $0.73 \mu$ mole sialic acid/mg., $0.31 \mu$ mole hexosamine/mg. This material was ninhydrin-negative, and contained less than $0.4 \%$ protein according to the method 
of Lowry et al. (1951). It showed a single peak on electrophoresis (Fig. 1 (ii)) and ultracentrifugation (Fig. 2 (i)), but on paper chromatography (Fig. 6c) several substances were detected. Spots 4 and 5 were much fainter than spots 1,2 and 3. Spots 3, 4 and 5 were non-metachromatic and stained blue-mauve, spots 1 and 2 were metachromatic and stained pink-mauve.

Column chromatography. Mallinckrodt's Analytical Reagent Silicic Acid 100 mesh (Savory and Moore, London) was ground to $\mathbf{3 0 0}$ mesh and treated according to Hirsch \& Ahrens (1958). Silicic acid (10 g.) was suspended in $35 \mathrm{ml}$. chloroform, poured into tubes, $1.5 \mathrm{~cm}$. diameter, $25 \mathrm{~cm}$. long, and washed with a further $50 \mathrm{ml}$. chloroform. Ganglioside was dissolved in $6 \%(\mathrm{v} / \mathrm{v})$ methanol in chloroform and loaded on the column, at not more than $25 \mathrm{mg}$./g. sialic acid. Elution was performed with methanol + chloroform mixtures of stepwise increasing methanol concentration as indicated below. The chloroform used was washed with water, dried with $\mathrm{CaCl}_{2}$ and distilled before use; methanol was distilled before use.

Paper chromatography. Schleicher \& Schull 2045 B smooth paper (GallenkampTowers, London) was used, in strips $20 \mathrm{~cm}$. long and $11 \mathrm{~cm}$. wide, after washing overnight with $5 \%(\mathrm{v} / \mathrm{v})$ acetic acid by descending chromatography, followed by washing with water and air drying. Samples (200 $\mu$ g.) dissolved in $10 \mu \mathrm{l}$. water were placed on the papers in $1 \mathrm{~cm}$. streaks and the chromatograms developed by the ascending technique with freshly prepared mixtures of di-iso-butylketone, acetic acid, $\mathrm{H}_{2} \mathrm{O}$ (40:30:7, v/v; Marinetti \& Stotz, 1956), in tightly closed cylindrical jars, $21 \mathrm{~cm}$. high, $12.5 \mathrm{~cm}$. diameter. After overnight running the papers were air dried, stained by immersion in $0.02 \%(\mathrm{w} / \mathrm{v})$ cresyl violet in $1 \%(\mathrm{v} / \mathrm{v})$ acetic acid in water and heating at $60^{\circ}$ for $10 \mathrm{~min}$., and washed with $1 \%(\mathrm{v} / \mathrm{v})$ acetic acid. This dye stains lipids, acid lipids showing metachromasy, particularly in wet papers.

Analyses. Sialic acid was determined by the resorcinol method of Svennerholm $(\mathbf{1 9 5 7} b$ ), with $N$-acetylneuraminic acid (kindly supplied by Professor G. Blix and Dr L. Svennerholm) as a standard. Hexosamine was determined by the Procedure A of Svennerholm $(1956 \mathrm{~b})$, with glucosamine hydrochloride as a standard.

Ultracentrifugal studies. The Spinco Model E Analytical Ultracentrifuge, with the RTIC unit and a phase plate in the schlieren-optical system, was used. Toxin and ganglioside were dissolved in $0 \cdot 1 \mathrm{M}$-phosphate buffer $(\mathrm{pH} \mathrm{7 \cdot 0)}$. The temperature of the rotor varied in different runs from $18^{\circ}$ to $21^{\circ}$. Runs were carried out at 59,780 $\mathrm{rev} . / \mathrm{min}$. for $23 \mathrm{~min}$. in single sector cells and at $42,040 \mathrm{rev} . / \mathrm{min}$. for $60 \mathrm{~min}$. in double sector cells. Areas under the peaks of the schlieren diagrams (phase plate angle $60^{\circ}$ ) on the photographic plates were measured by projecting the diagrams in a photographic enlarger with an enlargement of 10 diameters, tracing the diagrams on paper, drawing a midline through the thickness of the phase-plate lines, and measuring the areas so enclosed by means of a polar planimeter with an accuracy of $\pm \mathbf{0 . 5} \%$. The schlieren diagrams shown in this paper are derived from these tracings.

Electrophoresis. The Antweiler microelectrophoresis apparatus, with schlieren optical attachment (Boskamp; Shandon, London), was used. Samples were dissolved in 0.05 $\mathrm{m}$-phosphate buffer ( $\mathrm{pH} \mathrm{7.0)}$ ) and dialysed against the same buffer and subjected to electrophoresis at $75 \mathrm{v}$. for $10 \mathrm{~min}$. 


\section{RESULTS}

Studies on the combination of toxin and ganglioside

Electrophoretic studies. In previous studies (Van Heyningen, 1959b) the reaction between the water-soluble tetanus toxin and water-soluble ganglioside was demonstrated in the preparative (Spinco Model L) ultracentrifuge by determining the

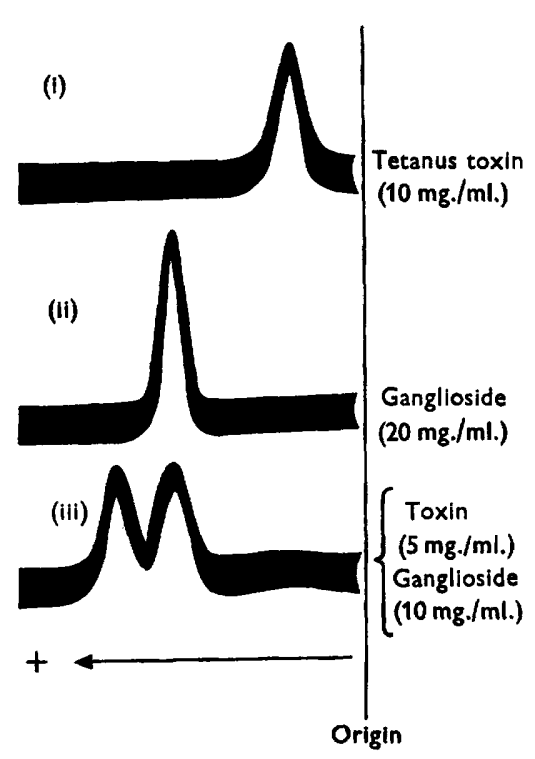

Fig. 1
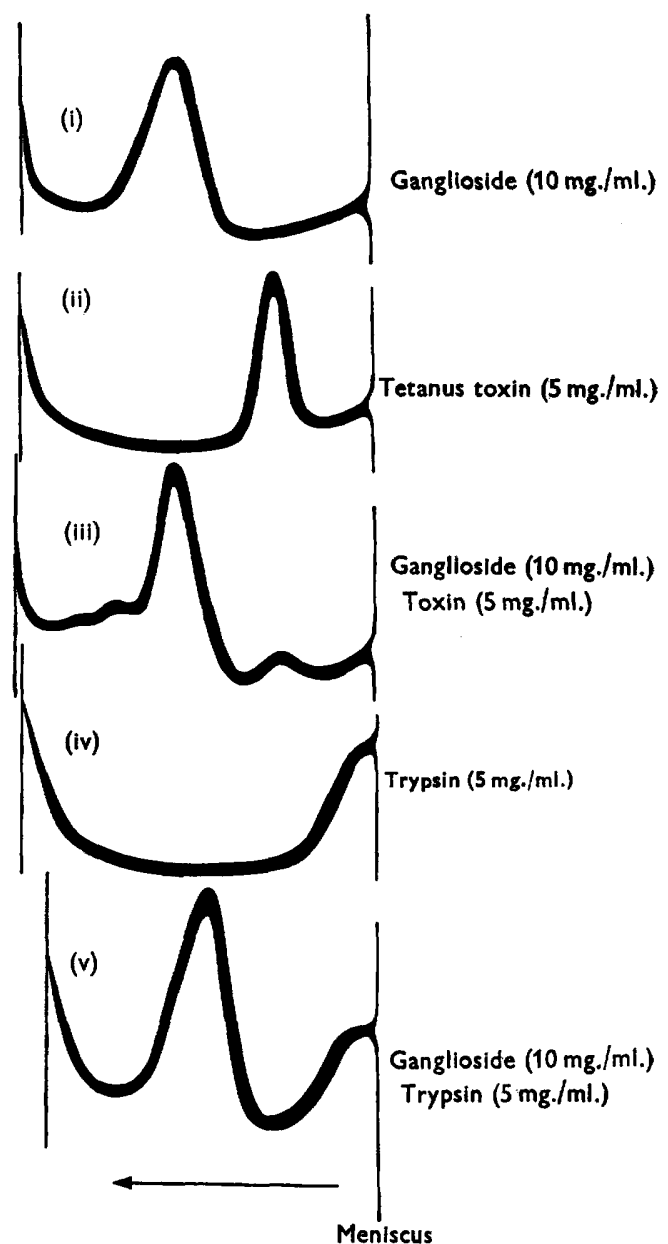

Fig. 2

Fig. 1. Fixation of tetanus toxin by ganglioside demonstrated by boundary electrophoresis. Fig. 2. Fixation of tetanus toxin, and non-fixation of trypsin, demonstrated in the analytical ultracentrifuge.

effect of the more rapidly sedimenting ganglioside on the rate of migration of the toxin from the upper to the lower half of the centrifuge tube. This was done by measuring the protein contents of the upper and lower halves of centrifuge tubes after centrifuging the toxin at 40,000 rev./min. for $1 \mathrm{hr}$. in presence and absence of ganglioside. The combination of toxin and ganglioside can also be demonstrated by 


\section{The fixation of tetanus toxin by ganglioside}

electrophoresis. Fig. 1 (i) shows that toxin alone migrated towards the positive pole much more slowly than ganglioside (Fig. 1 (ii)). Fig. 1 (iii) shows that when toxin and ganglioside were mixed the more slowly moving toxin peak was absent and instead a complex of peaks appeared, moving at about the same rate as ganglioside.

Ultracentrifugal studies; qualitative. The combination of toxin and ganglioside can also be demonstrated in the analytical ultracentrifuge. Fig. 2 (i) shows that ganglioside alone sedimented faster than toxin alone (Fig. 2 (ii)). Fig. 2 (iii) shows the sedimentation diagram of a mixture of toxin and ganglioside. The slowly moving toxin peak has almost disappeared (see section quantitative below), and we now have a complex of peaks sedimenting as fast as, and faster than the ganglioside peak, since complexes of greater molecular weight than ganglioside alone are formed. Fig. 2 (iv) shows that under the same conditions of centrifugation the peak of trypsin, a protein which does not combine with ganglioside at the buffer concentration used (see van Heyningen 1959 $a$ ), did not move completely away from the meniscus. Fig. $2(v)$ shows that the sedimentation of trypsin, unlike that of tetanus toxin, was unaffected by the presence of ganglioside.

The following substances were found not to fix tetanus toxin. (1) Sialic acid-free ganglioside, prepared by acid hydrolysis of brain ganglioside and kindly supplied by Professor E. Klenk. (2) Brain ganglioside in which the carboxyl groups of the sialic acid residues had been methylated with diazomethane. When this substance was saponified (in $0.1 \mathrm{~N}-\mathrm{NaOH}$ for $2 \mathrm{hr}$. at $37^{\circ}$ ) it fixed toxin again. (3) Sialic acid alone (the preparative ultracentrifugal technique was used for this demonstration; although $40 \%$ of the toxin in the upper half of a centrifuge tube migrated to the lower half during spinning for $2 \mathrm{hr}$. at $40,000 \mathrm{rev} . / \mathrm{min}$., no measurable amount of sialic acid migrated in the presence or absence of toxin under the same conditions). (4) Ovine mucoid substance with a sialic acid content of c. $0.5 \mu \mathrm{mole} / \mathrm{mg}$. and a molecular weight of $c$. 40,000, kindly supplied by Professor Gunnar Blix. (5) Hexosamine-free ganglioside from horse red blood cells (Klenk \& Lauenstein, 1953), kindly supplied by Professor E. Klenk.

Ultracentrifugal studies; quantitative. The qualitative demonstration of the fixation of toxin by ganglioside in the analytical ultracentrifuge led to the development of a quantitative assay of toxin-fixing capacity. This involved centrifuging a mixture of toxin and ganglioside and determining the concentration of toxin not fixed, by measuring the area of the toxin peak in the schlieren diagram. This area is a linear function of the concentration of toxin. These measurements require that the baselines of the peaks should be accurately delineated, and for this purpose double-sector cells were used, with buffer in one sector (to give the base lines) and the solution of toxin and ganglioside in buffer in the other (to give the peaks). Double sector cells cannot be spun at speeds greater than 42,040 rev./min. Fig. $3 a$ shows the series of schlieren diagrams obtained when constant concentrations of $5 \mathrm{mg}$. toxin protein/ $\mathrm{ml}$. were mixed with concentrations of ganglioside increasing from 0-10 mg. $/ \mathrm{ml}$. With increasing ganglioside concentration the area of toxin peak progressively decreased as more toxin was sedimented with the ganglioside. At concentrations of $2 \mathrm{mg}$. ganglioside/ml. and above there was no further decrease in the area of the toxin peak and a peak of constant size remained, corresponding in area to $25 \%$ of the original peak. This residual peak is due to the $25 \%$ of non-toxic protein in the toxin preparation (75\% pure, see Methods) which is not fixed by the ganglioside. 
It is interesting to see in these diagrams that the rapidly sedimenting gangliosidetoxin peaks are complex, representing several ganglioside-toxin combinations, and that the smaller the concentration of ganglioside the greater the speed with which the complexes sedimented. (Control experiments showed that the rate of sedimentation of ganglioside alone was independent of concentration.) Presumably at high ratios of toxin to ganglioside more toxin is fixed per unit weight of ganglioside and consequently the weight of the resultant particle is greater.

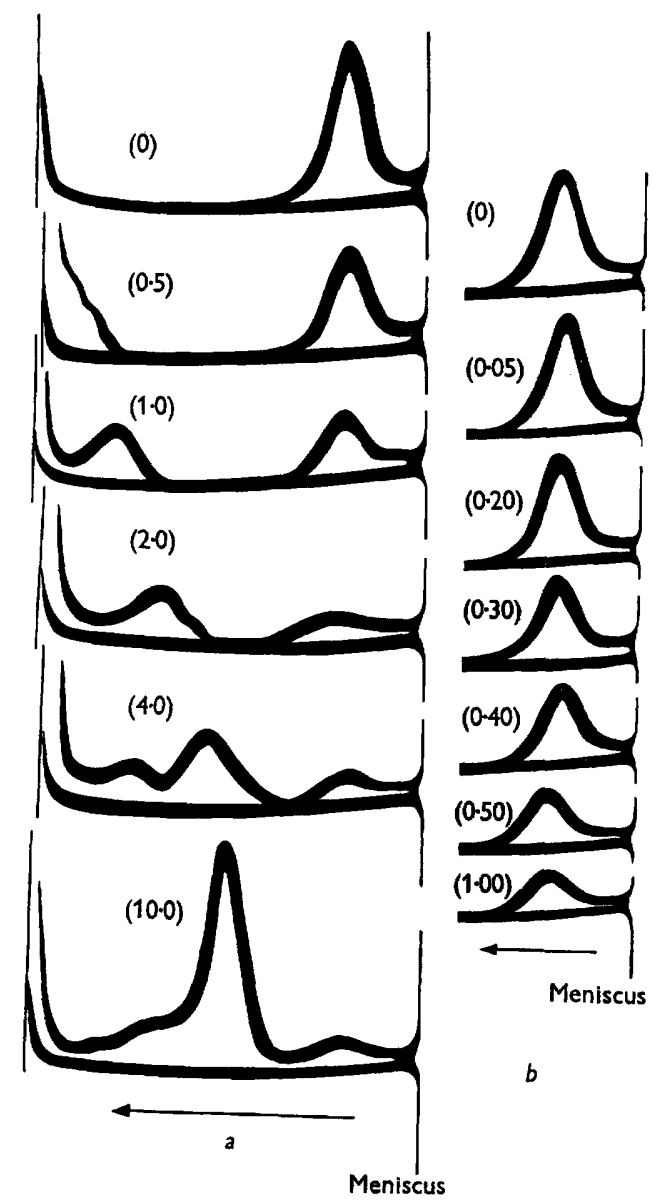

Fig. 3. Quantitative assay of toxin fixation by ganglioside in the analytical ultracentrifuge. Toxin protein concentration $5 \mathrm{mg} . / \mathrm{ml}$. in all cases, ganglioside concentration (mg./ml.) shown in brackets. $a$, Wide range of ganglioside concentrations; $b$, toxin protein peaks after treatment with smaller range of ganglioside concentrations.

To provide a quantitative assay of toxin-fixing capacity, a smaller range of ganglioside concentrations was mixed with constant concentrations of $5 \mathrm{mg}$. toxin protein/ $\mathrm{ml}$. Fig. $3 b$ shows the peaks of the unfixed protein during centrifugation. From the areas of these peaks the amounts of unfixed protein, and thus of fixed protein, were calculated. (In 10 separate experiments the values obtained for the area due to $5 \mathrm{mg}$. toxin protein, including pipetting errors, were $31 \cdot 6,34 \cdot 5,32 \cdot 4,29 \cdot 8,33 \cdot 8,32 \cdot 8,32 \cdot 7$, 
32.8, 31.2, 81.4; mean $32 \cdot 3 \mathrm{~mm} .{ }^{2}$ ). The points in Fig. 4 show the relation between amount of ganglioside and amount of toxin fixed. Evidently the curve through these points is very steep at low concentrations of ganglioside. Where the data are replotted to show weight of toxin fixed per unit weight of ganglioside (on the ordinate) as a function of weight of toxin fixed per unit volume, the intercept with the ordinate (i.e. infinite ratio of unfixed toxin to ganglioside) corresponds to a value of $23.5 \mathrm{mg}$. toxin fixed/mg. ganglioside (or $1 \mathrm{~mole}$ toxin $/ 2$ mole ganglioside). The (unbroken) curve in Fig. 4 is the Standard Curve obtained by replotting the smooth (broken) curve drawn through the points in this figure, with mg. toxin fixed on the ordinate and Receptor Units on the abscissa. The Receptor Unit (RU) is defined as the amount of ganglioside that fixes $20 \mu \mathrm{g}$. tetanus toxin $(=10 \mathrm{~L}+$ units toxin at $2 \mu$ g. toxin/L + unit; see van Heyningen, $1959 a$ ) at an infinite ratio of toxin to

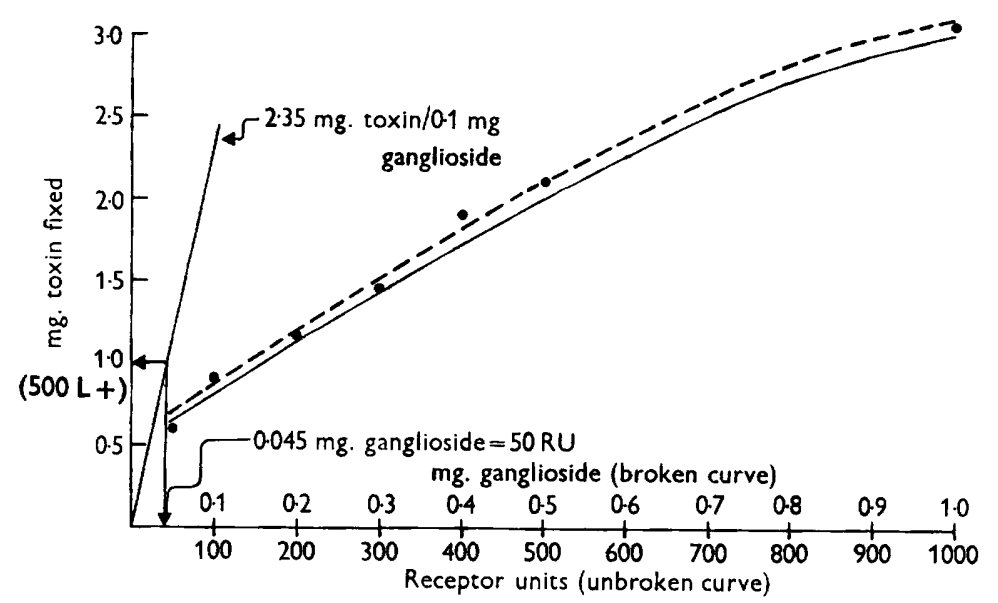

Fig. 4. Relation between weight of toxin fixed and weight of ganglioside used (broken curve), and the Standard Curve (unbroken) derived from these data.

ganglioside. (The RU now defined differs to an unknown degree from the RU previously defined under different conditions for the insoluble ganglioside + cerebroside receptor complex; van Heyningen, 1959 a). The steps in determining the RU content of a ganglioside preparation are now as follows. To one $0.25 \mathrm{ml}$. volume containing $25 \mathrm{mg}$. tetanus toxin preparation TD 464 D (i.e. $10 \mathrm{mg}$. toxin protein)/ml. $0.1 \mathrm{M}$-phosphate buffer ( $\mathrm{pH} 7$ ) is added $0.25 \mathrm{ml}$. buffer, and to another $0.25 \mathrm{ml}$. volume of toxin solution is added $0.25 \mathrm{ml}$. of a ganglioside solution of appropriate concentration in buffer. A portion ( $0.4 \mathrm{ml}$.) of the solution containing toxin only is placed in one sector of the double sector wedge cell, and $\mathbf{0 . 4} \mathrm{ml}$. of the ganglioside + toxin solution is placed in one sector of the double sector standard cell. Buffer $(0.4 \mathrm{ml}$.) is placed in the remaining sectors of each cell. The cells are then spun at

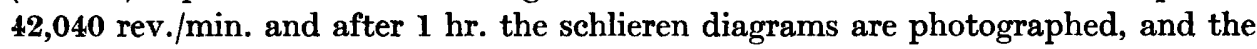
areas of the protein peaks measured. From the decrease in area due to the presence of ganglioside the mg. protein fixed is calculated and from this value the RU content of the ganglioside preparation is derived from the Standard Curve (Fig. 4). 


\section{Purification of ganglioside}

The partially purified sample of ganglioside (0.73 $\mu$ mole sialic acid, $0.31 \mu$ mole hexosamine, $1100 \mathrm{RU} / \mathrm{mg}$.; see Methods) was further purified by chromatography on a column of silicic acid by a procedure recommended by $\mathrm{Dr} \mathrm{L}$. Svennerholm. Ganglioside (200 mg.) was dissolved in a minimum volume of $6 \%(\mathrm{v} / \mathrm{v})$ methanol in chloroform, and the column successively eluted with $50 \mathrm{ml} .10 \%, 50 \mathrm{ml} .25 \%$ and $150 \mathrm{ml} .50 \%(\mathrm{v} / \mathrm{v})$ methanol in chloroform. The eluate was collected in $10 \mathrm{ml}$. volumes and the sialic acid content determined. The ganglioside all emerged in the $50 \%(v / v)$ methanol eluate (Fig. 5). Evidently it was still inhomogeneous with respect to sialic acid content and toxin-fixing capacity, although the hexosamine

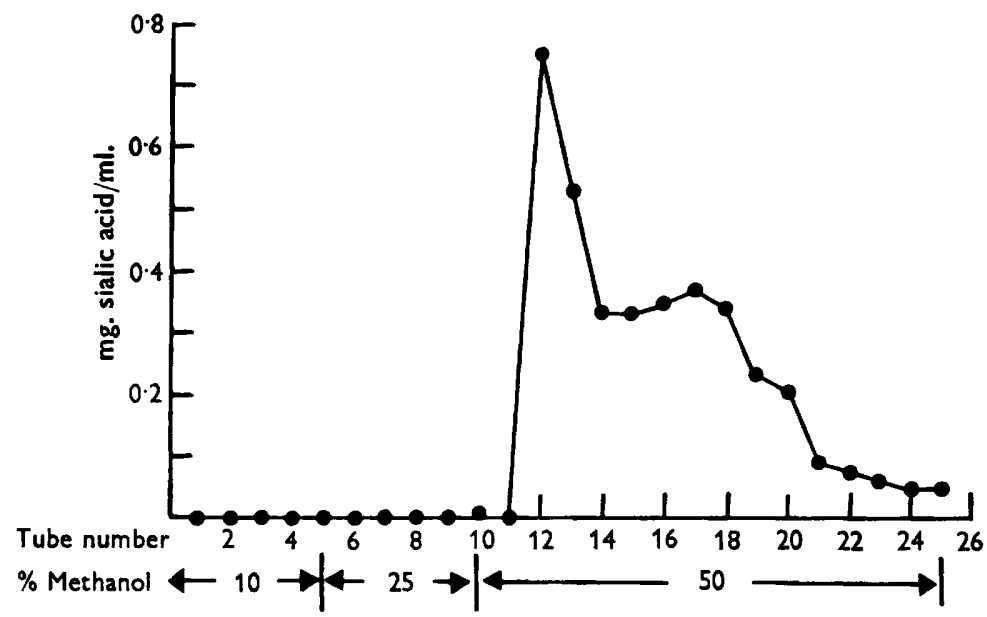

Fig. 5. Inhomogeneity of ganglioside emerging in $50 \%$ methanol in chloroform eluate from silicic acid column.

content of the material in all the tubes appeared to be constant (Table 2). On paper chromatography the pooled material from the $50 \%$ methanol eluate showed spots in positions 1,2 and 3, and spots 4 and 5 were absent (compare Fig. $6 c$ ). This material was placed on a fresh column of silicic acid, and after elution with $50 \mathrm{ml} .10 \%(\mathrm{v} / \mathrm{v})$ methanol in chloroform and $50 \mathrm{ml} .25 \%$ methanol it was eluted with $30 \%$ methanol likewise in chloroform. Ganglioside first emerged in the $\mathbf{3 0} \%$ methanol eluate and the column was eluted with this solvent (c. $200 \mathrm{ml}$.) until only negligible quantities of sialic acid-containing material emerged. Seventy-five mg. of material, which we shall call 'fast' ganglioside, was recovered in the $30 \%$ methanol eluate. The column

Table 2. Data on ganglioside preparations eluted from a silicic acid column with $50 \%(v / v)$ methanol in chloroform (see Fig. 5)

$\begin{array}{ccccc}\text { Pooled tubes } & \begin{array}{c}\text { Hexosamine } \\ (\mu \text { mole } / \text { mg. })\end{array} & \begin{array}{c}\text { Sialic acid } \\ (\mu \text { mole } / \text { mg. })\end{array} & \begin{array}{c}\text { RU/mg. } \\ \text { RU/ } / \mu \text { mole } \\ \text { sialic acid }\end{array} \\ \text { 12, 13 } & 0.27 & 0 \cdot 77 & 950 & 1234 \\ 14,15 & 0 \cdot 26 & 0 \cdot 88 & 1090 & 1314 \\ 16-25 & 0.28 & 0 \cdot 88 & 1170 & 1330\end{array}$


was then eluted with $200 \mathrm{ml} .50 \%$ methanol, and $90 \mathrm{mg}$. 'slow' ganglioside was recovered. Diagrams of the paper chromatograms of the 'fast' and 'slow' preparations are shown in Fig. 6, $a$ and $b$. The 'fast' preparations consist mainly of the nonmetachromatic material (spot 3), and the 'slow' mainly of metachromatic material (spot 1). Both preparations contained a proportion of the metachromatic component 2. The metachromatic and non-metachromatic materials were eluted from

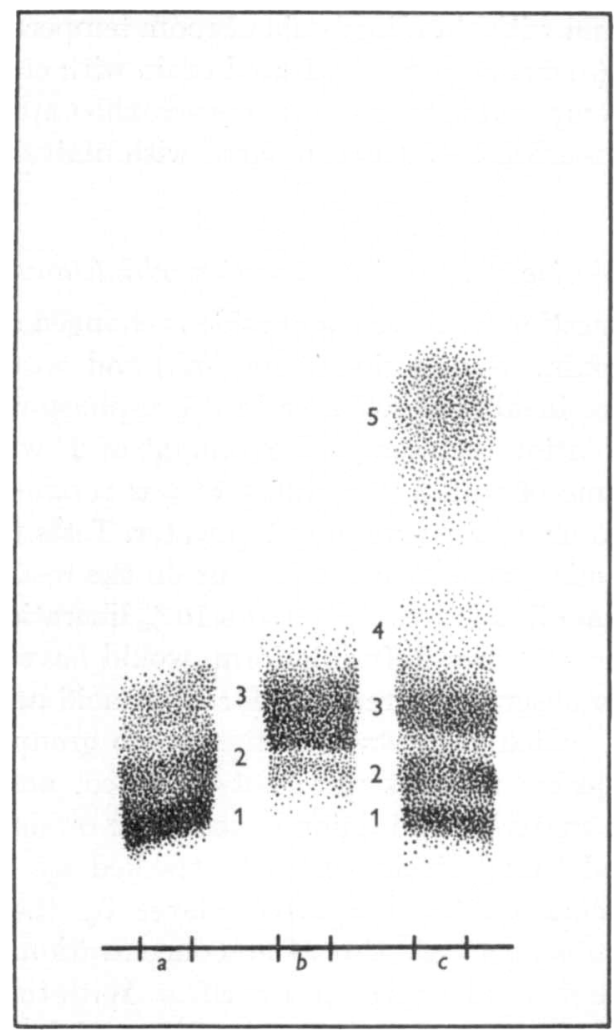

Fig. 6. Paper chromatograms of 'slow' $(a)$, 'fast' (b), and partially purified (c), preparations of ganglioside. Developed by ascending technique in di-isobutyl ketone, acetic acid, water and stained with cresyl violet. Spots 1 and 2 metachromatic (pink-mauve) 3, 4 and 5 non-metachromatic (blue-mauve).

the paper and rechromatographed, separately and together, and no interconversion was observed. Both 'slow' and 'fast' preparations have the same hexosamine content $(0 \cdot 31 \mu \mathrm{mole} / \mathrm{mg}$. in 'slow', $0 \cdot 30 \mu \mathrm{mole} / \mathrm{mg}$. in 'fast'), but the 'slow' ganglioside contains more sialic acid ( $0.93 \mu \mathrm{mole} / \mathrm{mg}$.) and has a greater toxin-fixing capacity (1310 RU/mg.) than the 'fast' ( $0.75 \mu$ mole sialic acid/mg., $950 \mathrm{RU} / \mathrm{mg}$.). We have observed similar differences in chromatographic properties, sialic acid content and toxin-fixing capacities between ganglioside preparations of other workers. Thus a mucolipid preparation provided by Dr Erwin Chargaff was mainly 'slow' and metachromatic on paper chromatography and contained $0.89 \mu$ mole sialic/mg and $1190 \mathrm{RU} / \mathrm{mg}$., whereas a ganglioside preparation provided by Professor E. Klenk was mainly 'fast' and non-metachromatic and contained $0.66 \mu$ mole sialic acid/mg. 
and $540 \mathrm{RU} / \mathrm{mg}$. Since sialic acid is split off when ganglioside is heated at $100^{\circ}$ at pH 3, and possibly on prolonged standing in solution at room temperature (e.g. see Bogoch, 1958), we wondered whether the 'fast' ganglioside is a degradation product derived from the 'slow' by loss of sialic acid during preparation, or whether they both exist in nervous tissue. We were not able to change the relative proportions of 'fast' and 'slow' in ganglioside preparations by the following variations in procedure: (a) plunging chopped-up beef brain in dry ice-cooled acetone immediately after killing, as compared with standing brain at room temperature overnight before acetone-dehydration; (b) extracting dehydrated brain with chloroform-methanol at room temperature as compared with extraction in a Soxhlet apparatus; $(c)$ deionizing by treatment with Amberlite CG 50 as compared with dialysis at $\mathrm{pH}$ 1.4-3.

\section{Is ganglioside changed by interaction with tetanus toxin?}

We examined the question whether ganglioside is changed as a result of its interaction with tetanus toxin. Ganglioside (5 mg./ml.) and tetanus toxin (10 $\mu \mathrm{g}$., or $75,000 \mathrm{LD} \mathrm{50} / \mathrm{ml}$.) were incubated together in $0.1 \mathrm{M}$-phosphate buffer ( $\mathrm{pH} \mathrm{7}$ ) for $5 \mathrm{hr}$. at $37^{\circ}$ and the solution then dialysed overnight at $2^{\circ}$ with constant agitation against an equal volume of water. The diffusate was retained and dialysis of the residue continued for $5 \mathrm{hr}$. against running tap water. Tests for free amino groups, sialic acid and hexosamine were then carried out on the residue and the diffusate. The concentration of ganglioside was such that a $10 \%$ liberation of amino groups, or of hexosamine or sialic acid in a diffusible form, would have been detectable. The only positive reactions observed were those for sialic acid and hexosamine on the non-diffusible residue, which suggests that the amino groups of the hexosamine, sialic acid and sphingosine residues were not liberated, and that there was no liberation of diffusible material containing hexosamine or sialic acid. Bangham \& Dawson (1959) showed that lecithin was not attacked by lecithinase unless the positive charge was changed to a negative charge by the addition of various negatively charged substances at threshold concentration. Positively charged cations or amphiphatic molecules reversed the effect. With the thought that similar considerations of charge (either negative or positive) might apply to the possible enzymic cleavage of ganglioside, the experiments above were repeated in the presence of $0.02 \mathrm{M}-\mathrm{CaCl}_{2}$ (in which case collidine acetate buffer, $\mathrm{pH} \mathrm{6.8,} \mathrm{was} \mathrm{used),}$ and cetyltrimethylammonium bromide, sodium dodecyl sulphate, dicetylphosphoric acid, and saponin, all at $\mathbf{0 . 2 5} \mathrm{mg}$. $/ \mathrm{ml}$. None of these substances brought about any positive results. Since ganglioside occurs in extracts of nervous tissue in the form of a complex with cerebroside (van Heyningen, 1959 b) the same tests were carried out with ganglioside cerebroside complex, again with negative results.

Ganglioside (10 mg./ml. 0.05 M-phosphate buffer, $\mathrm{pH} 7$ ) was incubated overnight at $37^{\circ}$ in the presence and absence of tetanus toxin $(10 \mu \mathrm{g} . / \mathrm{ml} ., 75,000 \mathrm{LD} \mathrm{50} / \mathrm{ml}$.$) ;$ the two preparations behaved identically in the electrophoresis apparatus and in the analytical ultracentrifuge.

If tetanus toxin were an enzyme with ganglioside as its substrate, one would not expect the ganglioside to fix the toxin after the toxin had catalysed a change in it. This point was tested in the following way. An insoluble ganglioside + calcium + cerebroside complex was made (Van Heyningen, 1959 $b$ ) and suspended in water to 


\section{The fixation of tetanus toxin by ganglioside}

give a concentration of $1 \mathrm{mg}$. ganglioside/ml. To samples of this suspension were added equal volumes of $0.133 \mathrm{~m}$-phosphate buffer $(\mathrm{pH} 7)$ or a solution containing $1 \mathrm{mg}$. ( = 7 million LD 50) toxin/ml. 0.133 m-phosphate buffer (pH 7 ). These two mixtures were incubated for $16 \mathrm{hr}$. at $37^{\circ}$, spun at $5000 \mathrm{rev} . / \mathrm{min}$., the pellets washed with water, and the adsorbed protein removed with $0.1 \mathrm{~N}-\mathrm{NaOH}$. The ganglioside + calcium + cerebroside complexes which had thus been treated with toxin overnight and deproteinized with alkali, and the control preparation that had not been treated with toxin, were resuspended to the same concentration as before and again added to equal volumes of toxin solution and the amount of adsorbed protein measured in the manner previously described (van Heyningen, 1959 $a$ ). The receptor complex which had been treated with toxin adsorbed $88 \mu \mathrm{g}$. protein/mg. on the second suspension in toxin solution, and the control preparation $81 \mu \mathrm{g}$. protein $/ \mathrm{mg}$. It appeared therefore that the toxin-fixing capacity of the ganglioside + cerebroside complex was unaffected by treatment overnight with toxin at a concentration of 3.5 million LD 50/ml.

We also tested the possibility that complement might be fixed during the toxin + ganglioside interaction, but found that guinea pig complement (2MHD) still haemolysed sensitized sheep red cells after incubation with toxin + ganglioside mixtures. The toxin concentration ranged from $0.11 \mathrm{mg} . / \mathrm{ml} .(800,000 \mathrm{LD} \mathrm{50} / \mathrm{ml}$.) to $0 \cdot 000,000,4 \mathrm{mg} . / \mathrm{ml}$. (3LD 50/ml.) and the ganglioside concentration from $0 \cdot 4 \mathrm{mg} . / \mathrm{ml}$. to $0.05 \mathrm{mg} . / \mathrm{ml}$. The reagents were added in the order complement, toxin, ganglioside, $1 \mathrm{hr}$. at $37^{\circ}$, haemolytic system, $20 \mathrm{~min}$. at $37^{\circ}$.

\section{DISCUSSION}

In our most purified preparations of ganglioside at least three components have been observed on paper chromatograms, but on silicic acid columns only two were distinguished, and the absence of the third component was probably due to inadequate resolution. The three components have not been sufficiently separated from each other to merit a complete chemical analysis. The presence of adsorbed proteins might account for inhomogeneity on columns, but our preparations contain no proteins, and we believe we are dealing with at least three different gangliosides, and that irrelevant impurities have been removed. The 'fast' and 'slow' fractions separating on the silicic acid columns have the same hexosamine content, but differ in rate of movement and staining with cresyl violet on paper chromatography, in sialic acid content, and in toxin-fixing capacity. They contain the third, metachromatic, component in common.

The reported sialic acid contents of ganglioside vary (Table 1). Comparison of our preparations with those of others suggests that the preparation of Klenk \& Gielen (1960), which is a mixture of two gangliosides each containing $0.66 \mu$ mole sialic acid/mg., is 'fast' and non-metachromatic, whereas the preparation of Rosenberg \& Chargaff (1958), which contains more sialic acid (0.89 $\mu \mathrm{mole} / \mathrm{mg}$.) is 'slow' and metachromatic. We are not in a position to say whether the 'fast' and 'slow' gangliosides exist as such in nervous tissue, or whether the 'fast' is derived from the 'slow' by loss of some sialic acid during extraction and purification.

The fixation of tetanus toxin is dependent on the presence of the sialic acid residue in ganglioside, and, at least within the range provided by the 'fast' and 'slow' 
preparations, roughly proportional to the sialic acid content. The free carboxyl group of the sialic acid residue is essential for toxin-fixation.

The hexosamine-free ganglioside from horse red blood did not fix toxin, but this may be due to factors other than the absence of hexosamine, e.g. $N$-glycolyl rather than $N$-acetyl substituents in the sialic acid residues, differences in fatty acid residues, etc.

If tetanus toxin brings about a change in ganglioside it is by no means obvious. All the tests that we were able to devise to detect any change were negative and therefore inconclusive.

We are grateful to Dr A. Woodin for helpfully critical discussions; to Forskare L. Svennerholm for receiving one of us (W. E. van H.) in his laboratory and giving him invaluable advice on column and paper chromatography of gangliosides, as well as a sample of pure sialic acid; to Dr G. G. Pope and Dr R. O. Thompson for the tetanus toxin; to Professor G. Blix for samples of sialic acid and mucoid substances; to Professor E. Klenk for various ganglioside preparations; to Dr E. Chargaff for a sample of mucolipid; to the Oxford and District-Co-operative Society Ltd. for the supply of beef brain; to Mr J. Otway for technical assistance and to Mrs Galatea Collins for non-technical assistance. Very special thanks are due to the Wellcome Trustees for the most generous grant to W. E. van H. of the Spinco Analytical Ultracentrifuge and the Antweiler Microelectrophoresis apparatus. W. E. van $\mathbf{H}$. also acknowledges with gratitude that this work was assisted in part by a grant from the Office of Naval Research of the United States Department of the Navy (Project No. 103-474). P. A. M. was the John Simon Guggenheim Memorial Fellow.

\section{REFERENCES}

Bangham, A. D. \& Dawson, R. M. C. (1959). The relation between the activity of a lecithinase and the electrophoretic charge of the substrate. Biochem. J. 72, 486.

BoGoch, S. (1958). Studies on the structure of brain ganglioside. Biochem. J. 68, 319.

Folch, J., Arsove, S. \& Meath, J. A. (1951). Isolation of brain strandin, a new type of large molecule tissue component. $J$. biol. Chem. 191, 819.

Folch, J., Meath, J. A. \& Bogoch, S. (1956). Brain strandin. Fed. Proc. 15, 254.

Hirsch, K. \& Ahrens, E. H. (1958). The separation of complex lipide mixtures by the use of silicic acid chromatography. J. biol. Chem. 233, 811.

Klenk, E. \& Grelen, W. (1960). Zur Kenntnis der Ganglioside des Gehirns. Z. physiol. Chem. 319, 283.

KLENK, E. \& LAUEnstein, K. (1953). Über die Glykolipoide und Sphingomyeline des Stromas der Pferdeerythrocyten. Z. physiol. Chem. 295, 164.

Lowry, O. H., Rosebrough, N. J., Farr, A. L. \& Randall, R. J. (1951). Protein measurement with the Folin phenol reagent. J. biol. Chem. 193, 265.

MarinetTi, G. V. \& STotz, E. (1956). Chromatography of phosphatides on silicic acidimpregnated paper. Biochim. biophys. acta, 21, 168.

Meltzer, H. L. (1958). Three-phase counter-current distribution: theory and application to the study of strandin. J. biol. Chem. 233, 1327.

Rosenberg, A. \& Chargaff, E. (1958). A study of a mucolipid from brain. J. biol. Chem. 232, 1031.

Svennerholm, L. (1956a). Composition of gangliosides from human brain. Nature, Lond. 177, 524.

Svennerholm, L. $(1956 \mathrm{~b})$. The determination of hexosamines with special reference to nervous tissue. Acta Soc. Med. upsalien. 61, 287. 
Svennerholm, L. (1957 a). Quantitative estimation of gangliosides in senile human brains. Acta Soc. Med upsalien. 62, 1.

Svennerholm, L. (1957 $b$ ). Quantitative estimation of sialic acids. II. A colorimetric resorcinol-hydrochloric acid method. Biochim. biophys. acta, 24, 604.

van Heyningen, W. E. $(1959 a)$. Chemical assay of the tetanus toxin receptor in nervous tissue. J. gen. Microbiol. 20, 301.

van Heyningen, W. E. (1958b). Tentative identification of the tetanus toxin receptor in nervous tissue. J. gen. Microbiol. 20, 810 